\title{
Aircraft turbine engine control systems development: Historical Perspective
}

\author{
Jackson Lutambo ${ }^{1}$, Jiqiang Wang ${ }^{1,2}$, Hong Yue ${ }^{3}$, Georgi Dimirovsky ${ }^{4}$ \\ 1. Jiangsu Province Key Laboratory of Aerospace Power System, Nanjing Universityof Aeronautics \\ and Astronautics,Nanjing,210016, China \\ 2. AVIC Shenyang Engine Design \& Research Institute, Shenyang 110015, China \\ 3. The University of Strathclyde, Glasgow, UK \\ 4. Dogus University of Istanbul, Istanbul, Turkey \\ E-mail: jlutambo@rocketmail.com, jiqiang.wang@nuaa.edu.cn, hong.yue@strath.ac.uk, gdimirovski@dogus.edu.tr
}

\begin{abstract}
This paper describes the development of aircraft turbine engine control systems from the historical point of view to the present. With the increasing emphasis on aircraft safety, enhanced performance, and affordability, as well as the need to reduce the environmental effect caused by aircraft, there are many new challenges being faced by the designers of aircraft propulsion systems. The paper provides an overview of the various technological development activities in aircraft engine control and diagnostics, both current and some accomplished in the recent past. The motivations for each of the research efforts, the research approach, technical challenges, and the key progress to date are summarized.
\end{abstract}

Keywords: Control system, Gas Turbine Engine, Hydromechanical System, FullAuthority Digital Electronic Control (FADEC), Digital Electronic Engine Control (DEEC)

\subsection{Introduction}

The goal of any engine control system is to allow the engine to perform at maximum efficiency for a given condition. The complexity of this task is proportional to the complexity of the engine. Historically, jet engines have been controlled by hydromechanical control systems which consisted of simple mechanical linkages controlled by the pilot. As the engines have become more complex, with more control signals and higher demands on performance and functionality, electronic control systems have been introduced [1].The modern aero-engine used today for aircraft propulsion has evolved into its current form over the past 60 years, and Control technology has played a critical role in improving the performance, reliability, operating lifetime, and safety. Today all modern aero engines are controlled by Full Authority Digital Electronic control (FADEC) systems, or a combination of electronic and hydromechanical systems. The control functions implemented in many of these systems have not changed that much. The principle of using only fuel flow for speed control and limit the amount during transients, as in the first hydromechanical systems is

$\uparrow$ We wish to acknowledge the support of the Natural Science Foundation of Jiangsu Province (No. BK20140829); Jiangsu Postdoctoral Science Foundation (No.1401017B); and the Scottish Government which funded this project through the Royal Society of Edinburgh in partnership with the NNSFC; Fund for Science of Dogus University still the main control strategy in many systems. Other control signals are often open loop scheduled, or used only for limiting engine parameters. Interaction among the various control loops are most often neglected in the design of control law and the resulting problems are solved by a large number of fixes and special cases andthis still works satisfactorily for the engines used today [1].

The trend towards increasingly complex jet engines will undoubtedly continue in order to meet increasing demands on performance, fuel consumption and functionality. The interaction between the engine and aircraft systems will also increase, with missionspecific control and with the control of thrust direction. To utilize the potential of these engines, it is also necessary to use more advanced control concepts than conventionally used today. The trend is towards control concepts often referred to as 'smart engines' andthe multivariable controllers are most often the core of these advanced control concepts[1]. This paper discuss some of the developments which have taken place since the introduction of turbine engine as the main propulsion device on the aircraft with regards to the control systems.

\subsection{The birth of Turbine Engine Control Systems}

The 1930's saw the evolution of independent design and development work on gas turbine engines in Great Britain and Germany. Sir Frank Whittle patented his gas turbine engine in 1930 and after several years of development, a version of the same 
was first installed on an aircraft in 1941 [2]. Hans von Ohain had a patent for his engine in Germany in 1936 and the first flight with this engine had taken place in 1939 [2]. The first gas turbine engine developed by Whittle [2] had a simple throttle lever that controlled fuel flow into the engine. To accommodate the functional requirements when fitted on aircraft, design of fuel control system had to take into account effects of altitude, temperature and forward speed [3]. At the same time, continued requirements to improve gas turbine engine performance, production and life limiting processes had their impacts on gas turbine technologies [3]. In the $1950 \mathrm{~s}$, aircraft engine control systems were based on hydromechanical technologies and were complex artifacts. They encompassed a large number of components and subcomponents, and they were application-specific, such that a change in the design of the engine required a change in the design of the control system. Hydromechanical control systems reached a technological ceiling in a relatively short time. The maturity of the technology enabled engineers to understand, articulate, and modularize the interfaces between the engine and the hydromechanical control system. Furthermore, performance improvements derived primarily from operational experience rather than from scientific or technological breakthroughs had their impacts on turbine technology[4]. In the mature stage of development reached in the 1970s, hydromechanical control systems were characterized by a relatively low rate of technological change and increasingly predictable interdependencies with the other components. Although hydromechanical control systems had achieved relatively high reliability, they displayed limitations. Higher-thrustengines that were being developed during the 1970 s were characterized by a larger number of parameters that needed accurate measurement and computation. In particular, the increasing bypass ratio (i.e., the ratio of mass flow through the fan or bypass duct to that through the core) of the newly developed engines posed several problems for the calculation and control of thrust during engine operation. To avoid over-boost and over-temperature, more frequent adjustmentsof the power lever were required, and traditional hydromechanical control systems could not manage these problems. The complexity of thrust calculations, the high accuracy andquick-response time required, and the fact that most parameters (turbine temperature, fan speed, altitude) were available in electronic form therefore rendered digital electronics more suitable for control systems [5]. In order to introduce redundancy and enable greater safety in operation, certain electric supervisory devices and limiter controls were introduced. The subsequent growth of electronics and computer technology with their enhanced reliability enabled full authority digital electronics to be used. A historical perspective of the advancement in control technologies for aircraft gas turbine engines related to the US scenario has been outlined in [6]. A simple engine speedpower lever angle loop is illustrated in Figure 1.

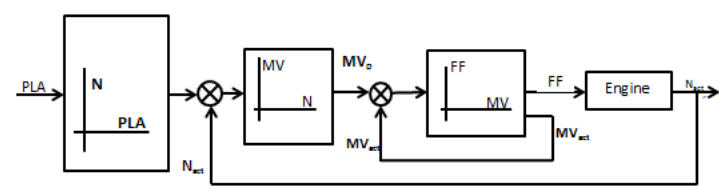

PLA - Power Lever Angle, FF - Fuel Flow, N - Rotational Speed, MV- metering valve, Nd - N-Demand, MVd - MVdemand, Nact $-\mathrm{N}$-actual, MVact $-\mathrm{MV}$-actual

Figure 1: Typical engine speed-Power Lever Angle (PLA) loop

\subsection{Hydromechanical Fuel Control}

The jet engine was first adopted as a source of thrust in aircrafts in the 1930s. Simple mechanical fuel controls comprising cams and levers were used in reciprocating engines, which constituted the majority at the time [9]. The control required by jet engines was comparatively complex, and the existing technology was inadequate. Even in the case of early post-war turbojet engines, variables of fuel flow or bleed valve could only be controlled. Subsequently, advances in the level of precision and miniaturization in the areas of mechanics and oil hydraulics led to progress in the control technologies of aircraft engines. Till the 1970s, the operating mechanism for engine control merely consisted of a hydromechanical system that combined mechanics, such as the axis, gear, spring, bellows, cam, governor, and valve adjustment screws, with fuel pressure [9].Hydromechanical control systems consist primarily of a fuel metering unit and an engine speed sensor. The fuel metering unit maintains even fuel pressure on both ends of the fuel metering valve by adjusting the fuel flow through the valve. This method of regulating fuel remains in use today, even though the mainstream technology has shifted to digital electronic controls. Engine RPM is detected through a mechanism in which the centrifugal force of a rotor governor directly connected to the enginedetects the displacement of the cam using a combination of springs and a device to measure fuel pressure. With advances in steam engine technology, a simple mechanism for RPM detection was already prevalent and was employed in jet engines, with changes in its material composition and additional miniaturization. Furthermore, a three-dimensional 
cam was developed with a notched surface that facilitated scheduled fuel control and variable stator vane revolution. Increased precision and miniaturization enabled the utilization of these systems in aircraft jet engines. However, the notched surface of three-dimensional cams did not facilitate the fine-tuning of the preset fuel schedule, and controlling it based on exhaust gas temperatures was difficult [9].

\subsection{Digital Electronic Engine Control (DEEC)}

Mechanical control systems when integrated with newer turbine engines suffered from the inherent limitations of tuning and adjustment beyond their physical defined limits. The electronic software based control thus offered distinct advantages, such as: Ease of adjustments of transient schedules/limiter schedules/Magnitude changes and slope changes in schedules/Changes in control logics. All these could be accomplished by changes of software build of the embedded controller in the electronic system [10]. Based on the redundancy management architecture, safe operation even with one lane nonoperational could be demonstrated. At the start of the gas turbine era, there had been only one control variable, namely, fuel flow. With advances in gas turbine cycles and technologies, the need for a greater number of control variables had slowly evolved over the decades.

The introduction of digital electronics progressively enlarged the role, importance, and functions of the engine control system as well as its interfaces with the other engine components and the airframe. The radical Technological shift led to a functional shift as Digital electronics is a fast moving technology. This high rate of advance enabled the embodiment in the control system of a large and increasing number of functionalities previously carried out by the pilot. The digital control system became the brain of the engine. In addition, digital control systems potentialities created new sets of technological imbalances between the control system and the engine power system. Although digital control systems interacted with, in fact, controlled a higher and enlarging number of engine components, these interdependencies were governed by the so called interface software. Due to this software component, digital control systems were not application-specific, and hardware and software modules could be reused in different applications. Digital control systems therefore exhibited predictable product systemic interdependencies, since such interdependencies were managed by the interface software [4].

DEEC was initially tested and evaluated by the NASA Dryden Flight Research Center from 1981 to 1983 in a joint endeavor with engine manufacturer Pratt and Whitney, the U.S. Air Force, and NASA's
Lewis Research Center (now the NASA Glenn Research Center) [11].The DEEC was developed for the Pratt and Whitney F100 turbofan engine, but its technology is now incorporated on other engine models. The DEEC replaced the F100 test engine's standard control system and had full control authority over a variety of engine functions.

Development of the DEEC is looked upon asa milestone in propulsion control, and a major transition from hydro mechanical to digital control.Benefits of the system are substantial and include reduced operating and maintenance costs, plus major boosts in engine performance and extended engine life[11].

\subsection{Full Authority Digital Electronic Control (FADEC)}

Full authority digital engine control (FADEC) is a system consisting of a digital computer, called an electronic engine controller (EEC) or engine control unit (ECU) and its related accessories that control all aspects of aircraft engine performance. FADECs have been produced for both piston and jet engines.True full authority digital engine controls have no form of manual override available, placing full authority over the operating parameters of the engine in the hands of the computer. If a total FADEC failure occurs, the engine fails. If the engine is controlled digitally and electronically but allows for manual override, it is considered solely an EEC or ECU. An EEC, though a component of a FADEC, is not by itself FADEC. When standing alone, the EEC makes all of the decisions until the pilot wishes to intervene.

FADEC works by receiving multiple input variables of the current flight condition including air density, throttle lever position, engine temperatures, engine pressures, and many other parameters. The inputs are received by the EEC and analyzed up to 70 times per second. Engine operating parameters such as fuel flow, stator vane position, bleed valve position, and others are computed from this data and applied as appropriate. FADEC also controls engine starting and restarting. The FADEC's basic purpose is to provide optimum engine efficiency for a given flight condition. FADEC not only provides for efficient engine operation, it also allows the manufacturer to program engine limitations and receive engine health and maintenance reports. For example, to avoid exceeding a certain engine temperature, the FADEC can be programmed to automatically take the necessary measures without pilot intervention.

With the operation of the engines so heavily relying on automation, safety is a great concern. Redundancy is provided in the form of two or more, separate 
identical digital channels. Each channel may provide all engine functions without restriction. FADEC also monitors a variety of data coming from the engine subsystems and related aircraft systems, providing for fault tolerant engine control. In flight, small changes in operation are constantly made to maintain efficiency. Maximum thrust is available for emergency situations if the throttle is advanced to full, but limitations can't be exceeded; the flight crew has no means of manually overriding the FADEC

\subsection{Advanced Engine Control}

With the success of the F100 Multivariable Control Synthesis (MVCS) and Advanced Detection, Isolation and Accommodation (ADIA) programs, there was renewed interest at GRC in investing in engine control technologies[11]. The Controls group grew significantly during the 1990s with a multitude of technology development efforts under various NASA programs and in collaboration with Air Force research programs. The research emphasis was on how to apply emerging multivariable and intelligent control approaches to provide improved functionality and performance for engines. The number of sensors and actuators on the engines continued to increase, thus providing an opportunity for advanced controls research. The continued advancement in computer technology also opened the possibilities of incorporating more complexity into the control logic in the FADECs. The idea of using active control of engine components to maximize the achievable performance throughout the operating envelope, and not be constrained to accept the suboptimal performance at other than design points, began to emerge. There was additional opportunity to investigate nontraditional uses of the engines, enabled through advanced controls, to increase aviation safety, and to start formulating engine control architectures that will help meet the challenging goals of increased efficiency and reduced environmental impact. Some of the significant accomplishments in the mid-1990s to early 2000s are described.

\subsection{Integrated Flight/Propulsion Control}

In the mid-1980s to $1990 \mathrm{~s}$, the trend in future military fighter/tactical aircraft design was towards

aircraft with new/enhanced maneuver capabilities such as short takeoff and vertical landing (STOVL) and high-angle-of-attack performance. An integrated flight/propulsion control (IFPC) system is required in order to obtain these enhanced capabilities with reasonable pilot workload.

The major design steps are (1) generation of integrated airframe/engine models for control design; (2) centralized control design, considering the airframe and engine system as an integrated system; (3) partitioning of the centralized controller into separate airframe and engine subcontrollers; (4) Operational flight envelope expansion through scheduling of the partitioned subcontrollers; (5) nonlinear design such as incorporation of limit logic for operational safety; and (6) full system controller assembly and evaluation. The approach was applied for IFPC design for a conceptual ASTOVL aircraft in the landing approach to hover transition flight phase [12]. During this phase the control of the aircraft transitions from forces and moments generated by aerodynamic control effectors to purely propulsion system generated forces and moments. Various technologies that are relevant to practical use of multivariable control design techniques were developed as part of the Methodology for Propulsion and Airframe Control IMPAC-based IFPC design study [12]. These are (1) a generic command tracking problem framework for robust control law synthesis using $\mathrm{H}$-infinity control design techniques with rules of thumb for selecting various frequency weights in the design procedure; (2) a systematic procedure for partitioning a centralized controller into decentralized, hierarchical subsystem controllers; (3) a simplified scheme for controller scheduling, which exploits the robustness properties of centralized/partitioned control designs; and (4) a modified scheme for designing integrator wind-up protection (IWP) gains, which guarantees closed-loop system stability for single-actuator saturation. An example result which shows application of the optimized IWP technique to the propulsion control portion of the STOVL IFPC design (Mattern andGarg 1992) is shown in Figure 4.
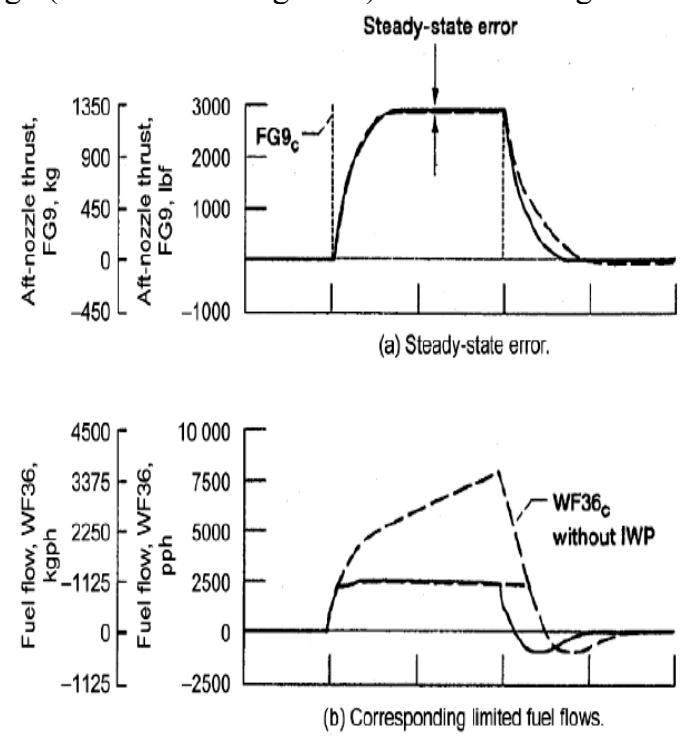

Figure 4.-Integrator wind-up protection for engine control (from Matternand Garg 1992; courtesy NASA). 
Shown are the responses of the aft nozzle thrust (FG9) to a step command and the corresponding fuel flow (WF36) requirement with and without the IWP. Without IWP (dashed lines), when the fuel flow limit is encountered, the fuel flow command continues to grow because of integrator wind up. As the FG9 command is reduced to zero, the integrator takes time to wind down and the FG9 response is degraded. With IWP active (solid lines), the fuel flow command tracks the fuel flow limit, and good FG9 tracking performance is obtained when the step command is removed. Although IMPAC methodology was successfully demonstrated by NASA, its application to current and future aircraft configurations was perceived as too complex during industry evaluation. However, the technologies developed for practical application of multivariable control design techniques were perceived to be of value by the industry and were transferred to industry through joint studies as documented in [13].

\subsection{Intelligent Life Extending Control}

With the desire to reduce engine operating cost, the industry is interested in developing technologies that will allow the engine and its components to operate (remain on wing) longer, thus increasing the time between engine overhauls. How the engine is controlled has a significant impact on the life of the components. Typically, the propulsion system control design engineer attempts to get the maximum performance out of the system while maintaining safe operation. Recent studies have shown that small changes in engine operating parameters, such as turbine inlet temperature, can have a significant impact on the damage accrued by engine components while having little to no effect on engine performance. GRC developed the concept of Life Extending Control where the engine control system is designed to achieve the desired performance while minimizing the damage accrued in engine components, hence maximizing the usable engine life.

\subsection{High Stability Engine Control (HISTEC)}

For aircraft engines, a safety margin, called the "stability margin," is built into the operation of the engine to prevent inception of fan/compressor stall due to inlet distortions caused by aircraft maneuvers or atmospheric disturbances. This stability margin results in a performance penalty being paid even at low distortion operating conditions such as cruise. Engine companies have estimated that being able to actively control the engine to safely maintain low stability margins under such low distortion operating conditions can result in reduction of 2 percent or more in specific fuel consumption.

\subsection{Active Stall Control}

The peak efficiency operating point of a turbine engine compressor is typically very near the compressor stall line as shown in Figure 5. In order to prevent catastrophic stall from occurring during large transients, the engine is operated with a sufficiently large safety margin. If the compressor can be safely operated closer to the designed compressor peak efficiency, then it will result in increased engine efficiency leading to significant savings in aircraft fuel costs. Even if compressor efficiency drops, cycle efficiency can be higher at higher overall pressure ratios. As shown in Figure 5, the compressor stall line can be moved up through active control thus allowing safe operation at peak efficiencies. Under the active stall control concept, however, the engine stall line is moved up through some active flow control. The active stall control is obtained by sensing pressure changes at the inlet face of the compressor, which will indicate flow distortion that is the precursor to stall, and activating high bandwidth flow valves located around the circumference of the compressor that blow high-pressure air to counter the flow distortion before it builds up to stall. The challenges for implementation of active stall control are developing accurate models of the stall phenomenon that can be used for control design, developing highbandwidth (on the order of $500 \mathrm{~Hz}$ ) actuators for controlling flow valves, and understanding the effectiveness of different actuating schemes for stall control.

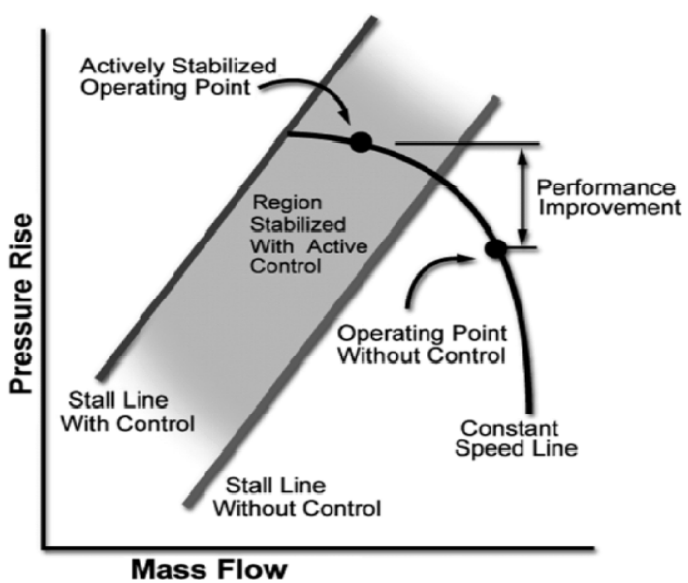

Figure 5.- Active stall control extends operating region forengines (image courtesy of NASA).

\subsection{Current Research}

Future turbine engines require more efficient consumption of energy, which is hindered by the added weight of the current turbine engine control systems. Currently research in advanced engine 
control technologies to replace the Full Authority Digital Engine Control (FADEC) system currently used by turbine engines is being undertaken. The intent was to investigate a solution which reduces energy consumption and increases efficiency of turbine engine operations. Active component control approaches such as active combustion control and active flow control for compression systems, and distributed engine control architecture are critical enabling technologies to meet the challenging goals of reducing aircraft engine emissions. Integrated control of inlet and engine systems is key for achieving safety and performance goals of high speed propulsion system. Intelligent propulsion control and diagnostics can significantly increase aircraft safety and improve operational reliability of space launch systems.All these are under study by various groups and individuals to improve turbine engine controls.

\subsection{Conclusion}

In conclusion, this paper provided a broad overview of the state-of-the-art of engine control, some significant past development of the engine controls that have resulted in increased efficiency and performance of aircraft engines, and some recent accomplishments where elements of the technologies developed can be expected to find their way into future aircraft engines.

\section{References}

[1] MelkerHarefors (1996). Multivariable Control Design For a Jet Engine: Volvo Aero Corporation, S-46181 Trollhattan, Sweden.

[2] Flack, R.D., Fundamentals of Jet Propulsion and Applications, Cambridge University Press, 2005.

[3] Balakrishnan S.R. (2013) Control System Development Experience for Aero Gas Turbine Demonstrator Engines. Gas Turbine Research Establishment, DRDO, Bangalore, India

[4] Prencipe, A (2000). Breadth and depth of technological capabilities in complex product systems: The

case of the aircraft engine control system." Research Policy, 29: 895-911.
[5] Griffiths, D. M., and R. D. Powell. The use of digital control for complex power plant management, AGARD Conference Proceedings N. 151, Power Plants Controls for Aircraft Gas Turbine Engines, Ustaoset, Norway.September.

[6] Link C Jaw and Sanjay Garg, Propulsion Control Technology Development in the United States, NASA/TM2005-213978

[7] Otto, E. W., and Taylor, B. L., III, (1950). "Dynamics of a turbojet engine considered as a quasi-static system." NACA Report 1011, NACA, Washington, DC,

[8] Ketchum, J. R., and Craig, R. T. (1952). Simulation of linearized dynamics of gas-turbine engines. TN-2826, NACA, Cleveland, $\mathrm{OH}$,

[9] Brusoni, S., Prencipe, A., \&Pavitt, K. (2001). Knowledge specialization, organizational coupling, and the boundaries of the firm: Why do firms know more than they make? Administrative Science Quarterly, 46, 597-621.

[10] Balakrishnan, S.R., Evolution of control systems for Aircraft Gas Turbine Engine under development, J. AeSI, 48(1) (1996), 94-104.

[11] Sanjay Garg (2013) Aircraft Turbine Engine Control Research at NASA Glenn Research Center. Glenn Research Center, Cleveland, Ohio USA

[12] Garg, S., and Mattern, D. L. (1994). "Application of an integrated methodology for propulsion and airframe control design to a STOVL aircraft." 94-3611, AIAA, Reston, VA.

[13] Watts, S. R., and Garg, S. (1995). "A comparison of multivariable control design techniques for a turbofan engine control." ASME 40th Gas Turbine and Aeroengine Congress and Exposition, Houston, TX.

[14] DeCastro, J. A., Litt, J. S., and Frederick, D. K. (2008). "A modular aero-propulsion system simulation of a large commercial aircraft engine," 2008-4579, American Institute of Aeronautics and Astronautics (AIAA), Reston, VA.

[15] Flack, R.D., Fundamentals of Jet Propulsion and Applications, Cambridge University Press, 2005.

[16] Whittle, F., The early history of the whittle jet propulsion gas turbine, The First James Clayton Lecture, I. Mech E, 1946. 